\title{
Following Instructions
}

\author{
Craig James Gunn \\ Department of Mechanical Engineering \\ Michigan State University \\ East Lansing, MI
}

\section{Introduction}

From the earliest records of humanity, the following of instructions has been at the apex of man's existence. Cave paintings show the correct ways to bring down a woolly mammoth. Clay tablets explain the intricacies of constructing tombs, important buildings, and cities. Biblical documentation presents detailed instructions in how to live one's life and the consequences of straying from the path. We are part of, and embedded in, a historical process that requires and rewards the following of instructions.

The historical legacy, though, seems to be lost on many of the students coming through the educational system today. More and more we see a total lack of regard for simple instructions and their importance in the real world. It is vitally important that a concentrated effort be made to instill in students the importance of reading and following instructions. It is obvious that this process should begin in the elementary grades, cultivated in the middle grades, and then finetuned in the college years. The reality may be that we at the university must take the responsibility of training our students to more actively read and follow instructions, an activity that will become increasingly more important as students compete for positions in the real world.

Early in every student's academic career the thought of breezing through assignment upon assignment has been short circuited by the amazingly easy process of simply failing to read and follow the instructions given in that assignment. This is compounded when the assignments become more critical for one's grade or the test that is being taken veers away from the objective because the test taker has failed to follow numbers 1, 5, and 8 in the list of steps to accomplish the task. We see on a daily basis student after student who arrive at one's office hours trying to argue for a "better" grade because they failed to read the single line that said either "document your work" or "complete the additional four problems on the back of the sheet." As one professor continually harangues, "This isn't rocket science, just follow the instructions!" I felt this way, too, until I realized that we are not facing one problem but two - students are generally not failing to follow the instructions; they are actually failing to even take the time to read those instructions.

\section{The Current State of Affairs}

The current state of web browsing and fast movement from one subject to another does nothing to instill in students a desire or need to read and follow instructions. If one misses a point, it may be picked up later - or so the browser thinks. This on top of the growing problem of student

"Proceedings of the 2002 American Society for Engineering Education Annual Conference \& Exposition Copyright (C) 2002, American Society for Engineering Education” 
behavior in the lower grades where instructors have given up requiring those younger students to do outside assignments because the instructor finds it much easier to simply walk everyone through the assignment in class. This requires no reading and following of instructions because they are fed to the students with no effort on their part.

This dilemma of students arriving at the university with inadequate skills must then be addressed in a two-front attack. Students must be both taught and encouraged to read those multitudes of instructions that are given by every instructor in every course and then comply with what the instructions require. This may seem to be a simple task for those who were raised in environments that cultivated the behavior of following instructions, but those individuals are usually well past the time of sitting in classrooms as students. It is definitely the college-age student that we must be concerned with along with their atrophied skills.

\section{Beginning Steps}

Even if many universities do not admit students to formal engineering programs until their junior year, most of these engineering schools provide some mechanism for students who have decided upon an engineering career as they enter the university. The preliminary engineering courses that these students enroll in can begin the process of retraining students to learn the benefits of following instructions and the necessity of this activity in the real world.

Early in the engineer's academic career, simple techniques can be utilized to focus students on the need to continue the practice of following instructions. One of the important issues is to make students actually see the importance and not just lecture on the need to follow instructions. One technique that can be accomplished in a relatively short class period is to have students write their own instructions on how to create an object, i.e., a paper airplane. They are not allowed to mention anything that will give the receiver of the instructions any indication that what he or she will have to create from the instructions is a paper airplane. By separating members of the class and using different colors of paper for the information to write instructions on how to build the paper airplanes, students will all feel that they are providing instructions on totally different projects. When the instructions are exchanged, no talking can be allowed and students must follow exactly the instructions given. At any point where they cannot continue the instructions because those instructions fail to give adequate directions, they must stop. These uncompleted airplanes can then be investigated and more improved instructions can be added within group discussion.

\section{Continuing the Process}

Fun with learning added in provides a quick message that if instructions are incomplete or incomprehensible no one can follow them. Students attempting to build the airplane with the instructions also quickly understand the importance of having a complete set of instructions in their work.

The instructor in the above case is not required to force students to listen to diatribes on the problems created when not following instructions. The instructor, on the other hand, can simply sit back and let the discussion unfold among the class members on why or why not a particular set of instructions accomplished the task of allowing a piece of paper to be transformed into a flying machine.

"Proceedings of the 2002 American Society for Engineering Education Annual Conference \& Exposition Copyright ( 2002, American Society for Engineering Education” 
There are also a myriad of short items that can be inserted into courses that show students the value of both reading and following instructions. These can be incorporated into other forms of interest for students where the value of following those instructions is a very subtle part of the process. Think of the myriad examples of logic puzzles that exist in books of all kinds. Puzzles that require students to carefully organize facts and assumptions into a logical answer will provide them with necessary tools in logic to move through problems. This movement is reflected in the same need to carefully comply with instructions given.

Two students, a junior male and a sophomore female, are sitting in the football stadium. "I'm a girl, "said the one with the red hair.

"I'm a boy, "said the one with the brown hair.

If at least one of the two students is lying, which student has brown hair and which student has red hair?

Students will have to carefully organize their thoughts into discerning that both individuals are lying and the boy has red hair and the girl has brown hair. The lesson given is that all the information must be carefully analyzed before a solution can be achieved. This directly correlates to the following of instructions - as individuals fail to follow each part of an instruction more and more error intrudes until a total breakdown of the project ensues.

Word finds, Anagrams, Crosswords, Brainteasers, frame games, and the above logic puzzles each require students to read and then carefully work through a variety of thought processes. They see the challenge and the fun of tackling these mind games and see a satisfaction in reaching conclusions that speak of their mental abilities. These activities can be fostered in every engineering course offered at the university and require no loss of class time or instruction. They are simply passed out to students and the challenge begins. The above types of activities provide students with subtle tools that carry over to the careful reading of more academic instructions.

It is also interesting that an older generation of instruction followers does not recognize the need to actually make an issue of following instructions. Printed pages are simply passed out with no concern for making sure that what is printed is clear to the receivers. Presenting instructions in class, discussing the issues involved in the assignment, and then requiring the students to actually use the instructions within the assignment add credence to the issue of instructions actually having an importance in the process. Focusing on those instructions before they are required to be used does much more than berating the students after the completion of the assignment or the lack there of. It is sometimes felt that students do not understand the importance of actually following instructions because they have simply never been told that this process is important and given reasons to substantiate the claim.

\section{Real World Studies}

Case studies where instructions have been circumvented or completely violated are good ways to get students to actually understand the importance of following instructions. One such case is the tragedy of the Challenger. While many issues have been discussed in regard to the challenger disaster, here we can focus on the serious problem that occurred because some very simple instructions never saw completion. This is reflected in a set of memos that were collected after the 
Challenger exploded. They show that problems with the construction of the spacecraft indicated that serious consequences could occur if they were not rectified. They were not, and the Challenger ended in disaster.

These are actual memos that were collected after the Challenger exploded. The compilation detailed the type of documentation that passed from engineers to administrators and how the breakdown in the following of procedures, otherwise instructions, cost the lives of a dedicated team of astronauts. If documentation such as this is presented to students, it is felt that they will more carefully attend to the job of reading and carefully following instructions. Collecting this kind of documentation could also provide students with interesting research. They could look at a multitude of disasters and investigate whether it was known if proper procedures or instruction following were practiced.

NATIONAL AERONAUTICS

NASA

SPACE ADMINISTRATOR

GEORGE C. MARSHALL SPACE FLIGHT CENTER

MARSHALL SPACE FLIGHT CENTER, ALABAMA

EP25 (83-119)

December 6, 1983

To: $\quad$ EE11/Mr.Horton

From: $\quad$ EP25/Mr.Miller

Subject: Request for Tests by the Contractor to Obtain Space Shuttle SRM Clevis Joint, Fixed Housing/Aft Segment Joint and igniter Adapter/Forward Segment Joint Leak Check Data It is requested that you take formal action to assure that the following tests are performed in a timely manner by the contractor, Morton/Thiokol, on SRM Hardware:

a. Case Clevis Joint Dual O-Ring Seal Leak Detection - Perform tests with full scale clevis joint hardware to obtain the following data as a minimum:

(1) Post assembly pressure in the zinc chromed sealant cavity.

(2) Determine minimum pressure and time required to position O-rings for 50psig-leak check. 


\section{UNITED}

\section{TECHNOLOGIES}

UNITED SPACE

BOOSTERS

\section{INTERNAL CORRESPONDENCE}

To: Larry Mulloy

Fm: George Morefield

Sj: $\quad$ Zinc Chromate Putty in SRM Joints

Dt: $\quad$ March 9, 1984

No: GSM-042-84

Following is an elaboration of my impromptu remarks in yesterday's FRR concerning burned primary pressure vessel "O" - rings.

I alluded to the Titan III SRM history which is quite similar to the current STS SRM experience. Post-fire inspection of Titan SRM static test motors showed that pressurization of the single "O" -rings routinely occurred via a single breakdown path across the joint putty......

On the few occasions when Titan motors were destacked it was found that the high hydraulic forces associated with joint mating actually caused case insulation to peel away from the case....

NATIONAL AERONAUTICS

NASA

\section{SPACE ADMINISTRATOR}

GEORGE C. MARSHALL SPACE FLIGHT CENTER

MARSHALL SPACE FLIGHT CENTER, ALABAMA

EPO1 (85-48)

March 7,1985

To: $\quad$ SA 41/ Mr. Mulloy

Thru: EE11/Mr.Horton

"Proceedings of the 2002 American Society for Engineering Education Annual Conference \& Exposition Copyright (C) 2002, American Society for Engineering Education” 
From: $\quad$ EPO1/Mr.McCool

Subject: $\quad$ Request for initiation of Testing to Provide Data for Resolving the Burned ORing Seal Problem on the Space Shuttle SRM

On December 6, 1983, this office requested via the referenced letter that the contractor obtain available full scale diameter, short stack hardware and conduct tests to provide data on zinc chromate putty behavior as related to affect on joint leak checks. Fourteen months have elapsed and no visible action has been taken to obtain and equip the short stack hardware although agreement was made to perform the test at the time of request........

The acquisition of joint putty lay-up and leak-check data on a high priority basis has become very important in view of the need to resolve the burned O-ring problems

The above memos take place over a period of 11/4 years. They reflect the lack of carry through of the administrators of Morton Thiokol. Instructions were carefully being relayed by conscientious engineers and those instructions perhaps were read but never followed. The result is a national tragedy.

\section{Checklists}

A last area that might improve the level of instruction following is to provide students with insights into the use of checklists. Everyone uses checklists in very visible ways, i.e., writing notes on one's hands or arms; or in more subtle ways, i.e., the subconscious checking that we all do before we leave our homes in the morning - making sure that we are dressed correctly and have all the materials we need for the day in our hands. When quizzed, students fail to remember that they actually thought about all the clothes that they put on; but very few classes contain students who have failed to wear any clothes at all, so the checking must be going on. Since these kinds of checklists exist, one can then move to the issue of checklists in relation to academic assignments. The following checklist asks students to simply reread a formal lab report before it is handed in and make sure that all the information requested is contained in the proper locations within the report. After completing this checklist, students were asked if they had actually made any changes to the text. All responded that they had added items to the original report. The discussion then led to what grade the first effort would have received and how this grade would have been improved with the changes made. The message of following instructions and receiving a reward for actually following instructions was made very clear. 


\section{Checklist given to mechanical engineering students:}

The following items make up the elements that will be evaluated in the formal reports for Mechanical Engineering 451 (Controls Class) from the composition side. Teaching assistants will comment on the inadequate elements, and you will have to address those comments.

In order to make this a smooth running operation, it will be necessary to number in the first submission where each of the following items are addressed in your text.

\section{TITLE PAGE}

1.Title of paper

2.Course

3.Date due

4.Section time

5.Name

6.DRAFT OR FINAL COPY

\section{SUMMARY}

7.Overview of the lab

8.Why was the lab performed?

9.How was the lab performed?

10. What was discovered, achieved, or concluded

11. Recommendations

12.Past tense used

13.Reference to experiment not paper

14.No personal reference ( $\mathrm{I}, \mathrm{We})$

15. It is before the Tale of Contents

TABLE OF CONTENTS

16.All sections represented

17.Abstract and Table of $\mathrm{C}$ not listed
18.Lab Observations as a heading Analysis,equip,procedure, results - sub headings

19.All columns lined up

\section{MOTIVATION AND OVERVIEW}

20.Ample motivation for the experiment stated

20A.yours

20B.Whirlwind's

21.Sufficient information to orient reader to the substance of experiment

22.Sections to follow mentioned

23.Any terminology that reader will need to understand the text.

\section{THEORETICAL BACKGROUND}

24.Mathematical model used to predict system behavior presented with ample explanation and lead in

25.equations numbered

26.punctuation with equations

(: with follow/s/ing only)

27.equations have space

EXPERIMENTAL SETUP AND PROCEDURE

"Proceedings of the 2002 American Society for Engineering Education Annual Conference \& Exposition Copyright (C) 2002, American Society for Engineering Education” 
28. Schematic of equipment used

29.Figures/Tables correct

(Figure 1. Title)

30.Figures oriented correctly

Clearly labelled and referenced

31.Highlights of equip. used

32.Highlights of the procedure (not specific steps)

\section{RESULTS AND DISCUSSION}

33.Data presented with clear indication of what data applies to

34.Reader will understand what this data refers to

35.Trends in data stated (then to be discussed in the discussion section)

36.Clear indication of what reader should see in the data

37.Complete discussion of the results

38.Connection of data and Whirlwind is clearly stated

39.Comparison to similar experiments is shown

40.Strong points of study given
41.Weak points of study given

42.Statements are specific

43.Logical progression to support

conclusions that follow

\section{CONCLUSIONS AND}

RECOMMENDATIONS

44."The following conclusions are supported by this study:"

45.Conclusions are numbered

46.Conclusions are concise and highly specific

47.Vague statements do not exist

48.Conclusions directly flow from discussion

\section{Final Thoughts}

We all are required to be concerned with instructions in our lives. These range from simple stop signs instructing us to come to complete stops to much more complicated procedures that must be followed in order to fly an airplane or complete a difficult surgical procedure. Following instructions has become an issue when it comes to teaching in the university setting. Students are becoming less and less inclined to both read and follow instructions. Through the use of simple tasks, enjoyable activities, and grade enhancing procedures; students should be able to regain a focus on following instructions both for their benefit and others.

"Proceedings of the 2002 American Society for Engineering Education Annual Conference \& Exposition Copyright (C) 2002, American Society for Engineering Education” 


\section{CRAIG JAMES GUNN}

Craig James Gunn is Director of the Communication Program in the Department of Mechanical Engineering at Michigan State University. In this role he directs the integrated communication program in mechanical engineering while providing help to the cooperative engineering education division of the College of Engineering. He has spent thirteen years of teaching in the public school system and fifteen years at Michigan State University. He serves as editor for the CED Newsbriefs and MCCE Co-op Courier. 